\title{
Core-shell LC-MS/MS method for quantification of second generation anticoagulant rodenticides diastereoisomers in rat liver in relationship with exposure of wild rats
}

Isabelle Fourel, Marlène Damin-Pernik, Etienne Benoit, Virginie Lattard

USC 1233 INRA-VetAgro Sup, Veterinary School of Lyon, 1 avenue Bourgelat, 69280 Marcy l'Etoile, France

\section{Abstract:}

Second generation anticoagulant rodenticides (SGARs), pesticides used worldwide to control rodent populations, exist in two diastereoisomer chemical species because they own two stereogenic centers. A core-shell LC-MS/MS multi-residue method for comprehensive quantitative analysis of the diastereoisomers of five SGARs as well as three first generation anticoagulant rodenticide molecules has been fully validated in liver of rats according to a bioanalytical guideline. A core-shell column (superficially porous particles) has been chosen for its ability to separate the diastereomers of bromadiolone, difenacoum, brodifacoum, flocoumafen and difethialone and for its robustness to rat liver extracts. The highly selective chromatographic separation of the diastereoisomers contributes to good signal to noise ratios and then enhances the sensitivity of the method compared to the ones of fully porous columns. An elution gradient has been optimized with $10 \mathrm{mM}$ ammonium acetate and acetonitrile as aqueous/organic mobile phase respectively. Triple quadrupole mass detector has been used to achieve specifity and LLOQ from 0.92 to $2.2 \mathrm{ng} / \mathrm{g}$ for each diastereoisomer, or first generation anticoagulant rodenticides. Then we evidenced diastereoisomeric ratios in liver of rats issued from not controlled exposure of wild rats (Rattus norvegicus) trapped in a French Parisian park through a campaign of rodent eradication. We compared them to diastereoisomeric ratios in SGARs commercial baits that contain both isomers, and showed that one of the two diastereoiomers had nearly disappeared in liver of rats. The proportions of cis-bromadiolone and trans-difenacoum were really lowered compared to the baits: 5/7 and 9/12 rats had only trans-bromadiolone and cis-difenacoum hepatic residues respectively. Liver persistence of the two diastereoisomers of bromadiolone and difenacoum was different due to differences in their pharmacokinetics in wild rats. The new Core-shell 
LC-MS/MS method is particularly well adapted for further exploration of diastereoisomers ratios in rodent and predatory wildlife biological samples in order to evaluate ecological consequences of actual baits, to explore new formulated baits with a good balance between efficacity (ability to kill rodents) and diastereoisomers persistence, and hopefully to mitigate exposure of non-target species.

Key words: Anticoagulant rodenticides, diastereoisomers separation, Core-shell LC-MS/MS, multiresidue validation, rat liver

Corresponding author: Isabelle Fourel

isabelle.fourel@vetagro-sup.fr

\section{Highlights :}

1) LC-MS/MS quantitative multi-residue method is fully validated to measure rodenticides

2) This method separates five pairs of diastereoisomers with a core-shell column

3) This method is a tool to explore diastereoisomers persistence in wildlife samples

4) Monitoring diastereoisomeric ratios from baits absorption to wildlife samples

5) Diastereoisomers ratios in liver of wild rats and rodenticides baits are different

\section{Introduction}

Anticoagulant Rodenticides (ARs) are used worldwide in urban settings and open field agriculture for rodent population control and are commercially available under the form of baits. 4-hydroxy coumarins/thiocoumarin and indanedione derivates are the active chemical substances of these baits. Chronologically, warfarin (W), coumatetralyl (CTTL) and chlorophacinone (CHL) constituted the first generation ARs in the 1950s. A few decades later, second-generation ARs (SGARs) were developed to overcome rodent resistance to first generation ARs, permitting a gain in pest control efficiency [1-4] but enhancing worldwide biological and environmental persistence, and risks of secondary wildlife poisonings [5-12]. 
SGARs i.e. bromadiolone (BROMA), difenacoum (DFM), brodifacoum (BFM), flocoumafen (FLO) and difethialone (DFTL) have the characteristic to own two asymmetric carbons in their chemical structure conferring these products to exist in two diastereoisomeric forms and thus four enantiomeric species [13-15]. Molecular structures of SGARs and stereogenic centers are presented in figure 1. In the last twenty years, special interests have been given to stereoisomeric chemical products, especially in pharmaceutical and pesticide, then environmental areas putting in light that they were chemically distinct and pharmacologically different in the living world [16]. They had hence to be treated as separate species and analytical methods were developped to characterize their dissociated physiological properties [17]. Numerous Liquid Chromatography on line with two dimensional Mass Spectrometry (LC-MS/MS) multi-residue methods have been published to quantify ARs in biological or environmental matrices [18-23]. Imran et al. [24] published a review of analytical methods for the determination of anticoagulant rodenticides in biological samples; none of them reported the quantification of SGARs diastereoisomers, even less SGARs enantiomers. Consequently no data is today available on SGARs diastereoisomers/enantiomers residues in rodent or non target wildlife after using them as biocide or plant protection purposes, although secondary poisoning evidences and large scale surveys have been documented in the past recent years [5-12].

Enantiomers have same chemical properties in an isotropic environment; they would then not be separated by means of achiral chromatography columns. Diastereoisomers with two chiral centers have same functional groups and similar but not identical chemical properties. Consequently, in sharp and well defined conditions, they theoretically may be separated on achiral columns. Hunter [25] examined the chromatographic properties of BROMA diastereoisomers in normal phase, reversed phase, ion pair and ion exchange chromatography. Some authors reported two resolved chromatographic peaks for BROMA diastereoisomers on $\mathrm{C} 8$ or $\mathrm{C} 18$ reversed phase columns in acidic conditions with acetate or formate ammonium ions in the mobile phase $[18,20,21,23,26]$ using only the first and major peak for the quantification of bromadiolone residue. But others reported only one chromatographic peak for BROMA on C18 reversed phase column in neutral or basic conditions [19, 27]. No multi-residue quantification method was produced for SGARs diastereoisomers even with Ultra-Performance Liquid Chromatography (UPLC) columns [22, 23].

Damin-Pernik et al. [14, 15] recently compared pharmacokinetics of both diastereoisomers of all SGARs by means of in vivo experiments on Sprague Dawley rats fed with only one or the two 
diastereoisomers, and put in light different pharmacokinetics, half-lives and persistence behaviours between them. Chromatographic separation of diastereoisomers was achieved by the means of $\mathrm{C} 18$ reverse phase column and phosphoric acid aqueous mobile phase which is not compatible with LCMS instruments, and with Ultra-Violet or Diode Array Detector. A different analytical method was used for each SGAR because it was impossible to achieve the chromatographic separation of the diastereoisomers of all SGARs with a single elution gradient. However more specificity and sensitivity are required to investigate field biological samples of wild rodents and non target species, firstly to screen the whole range of rodenticides possibly used as biocide or pesticide purposes, and secondly to show if this was possible to evidence a similarity of pharmacological and persistence behaviour for each pair of SGARs diastereoisomers between in vivo and field samples.

Core-shell particles as stationary phases in columns for liquid chromatography have been used in the past few years for analytical applications in biological matrices. The superficially porous particles with a solid silica core make their performance excellent compared to fully porous particles. Their mass transfer kinetics characterized by the Van Deemter equation have been described as similar to sub$2 \mu \mathrm{m}$ particles with the advantage of low back pressures [28-30]. It was pointed out the challenges for Core-shell particles were hanging out in the separation of isomers in complex matrices from biological and life sciences [28]. The aim of this work was to validate a comprehensive LC-MS/MS multi-residue method for the simultaneous quantification of eight ARs: three first generation ARs (warfarin, coumatetralyl, chlorophacinone) and the two diastereisomeric forms of five SGARs (bromadiolone, difenacoum, brodifacoum, flocoumafen, difethialone) according to the guideline on Bioanalytical Method Validation published by the European Medicines Agency (EMEA) [31]. The challenge was to find a chromatographic column able to separate five pairs of diastereoisomeric forms. It was achieved by using a Core-shell column, permitting to enhance selectivity and sensitivity compared with fully porous particle stationary phases. Triple quadrupole mass spectrometer detector permitted to acquire sensitive and specific signal. Hence, we were able to evidence diastereoisomeric ratios in liver of rats issued from not controlled exposure of wild rats trapped in a French Parisian park through a campaign of rodent eradication, and to compare them to diastereoisomeric ratios in SGARs baits in order to show possible differences in persistence of diastereoisomers in field samples. Actual anticoagulant rodenticides lead to heavy residues in rodents' body that enter the food chain and consequent secondary toxicity for predators and scavengers [5-12]. Differentiated persistence of diastereoisomers 
is then of special interest to decrease chemical impacts of these pesticides on non target wildlife [14, 15].

\section{Experimental}

\subsection{Chemicals and reagents}

W, CTTL, CHL, BROMA, DFM, BFM, FLO were supplied by Sigma-Aldrich (St Quentin Fallavier, France) as reference materials. DFTL was provided by Liphatech (Pont de Casse, France) with the diastereoisomers ratio. The ratios are the proportions of each diastereoisomer. For BROMA, DFM, BFM and FLO they were described on the manufacturer batch certificates of analysis. The ratios of all diastereoisomers were confirmed by LC-MS/MS i.e. the ratios obtained by normalization of the peak areas were in accordance with the ones of the manufacturers. Conventionally, the diastereoisomer which was named "Major" was the one the most present in commercial baits, and the other one was named "minor". Stereoisomeric assignation is reported in table 1 as determined by Damin et al $[14,15]$. Briefly, reference materials were purified on silica column and analyzed by NMR to allow determination of the retention time of each diastereoisomer.

HPLC-grade acetonitrile and methanol, acetone and hexane for analysis were supplied by Merck (Darmstadt, Germany), and ammonium acetate by Fluka (Steinheim am Albuck, Germany).

\subsection{Experimental animals for validation}

Six Sprague-Dawley rats were purchased from Charles Rivers (St Germain sur l'Arbresle, France) to provide blank liver of rats for method validation.

\subsection{Instrument and LC-MS/MS conditions}

Chromatographic analysis was performed on an Agilent 1200 series HPLC (Agilent Technologies, Santa Clara, CA, USA). Chromatographic separation was achieved on an Poroshell 120 StableBond C18 column $(2.1 * 100 \mathrm{~mm}, 2.7 \mu \mathrm{m})$ from Agilent Technologies at ambient temperature with a mobile phase of A: $10 \mathrm{mM}$ ammonium acetate and B: acetonitrile. The elution gradient was: $20 \% \mathrm{~B}(0 \mathrm{~min})$, 
30\%B (0.1 min), 40\%B (0.5min), 50\%B (5-11 min), 90\%B (11.5- 12.5min), 20\%B (13.5-25min). The flow rate was $0.25 \mathrm{~mL} / \mathrm{min}$. The injection volume was $1 \mu \mathrm{L}$, and the autosampler tray was at ambient temperature.

MS/MS detection was carried out by a 6410B Triple Quadrupole from Agilent Technologies equipped with ElectroSpray lonization source (ESI) in negative mode. The MS conditions were as follows: drying gas temperature $350^{\circ} \mathrm{C}$, drying gas flow $8 \mathrm{~L} / \mathrm{min}$, nebulizer pressure $40 \mathrm{psi}$, and capillary voltage $4000 \mathrm{~V}$. Fragment ions spectra were recorded in dynamic Multiple Reaction Monitoring (dMRM). Data collection and processing were performed with Masshunter ${ }^{\mathrm{TM}}$ Work-station from Agilent Technologies.

\subsection{Preparation of standard, calibration and $Q C$ samples}

Primary stock solutions of the 8 ARs were prepared in methanol at a concentration of $100 \mu \mathrm{g} / \mathrm{mL}$. A series of ARs working solutions in the concentration range of $0.01-10 \mu \mathrm{g} / \mathrm{mL}$ were obtained by further dilution with methanol. These working solutions were stored at $4^{\circ} \mathrm{C}\left(-18^{\circ} \mathrm{C}\right.$ for the primary stock solutions). The calibration samples were prepared by spiking different amounts of the appropriate working solutions into $0.50( \pm 0.01) \mathrm{g}$ of blank rat liver. Similar procedure was adopted to prepare quality control (QC) samples.

\subsection{Sample preparations}

\subsubsection{Preparation of liver extracts}

Solid-Liquid Extraction (SLE) was used to extract ARs from liver of rats. $0.50( \pm 0.01) \mathrm{g}$ of liver was weighed and homogenized with $10 \mathrm{~mL}$ of acetone using an UltraTurax. The mixture was centrifuged at 3000 rpm for $5 \mathrm{~min}$. The liquid part was evaporated to dryness at $40^{\circ} \mathrm{C}$ under a gentle stream of nitrogen. The residues were reconstituted in $1 \mathrm{~mL}$ of acetonitrile, and washed twice with $1 \mathrm{~mL}$ of hexane to discard the lipids. The remaining acetonitrile phase was evaporated to dryness in the same way as above. The residues were reconstituted with $200 \mu \mathrm{L}$ of acetonitrile, and filtered through a $0.2 \mu \mathrm{m}$ phenex filter (Phenomenex, Torrance, CA, USA) before LC-MS/MS analysis.

\subsubsection{Preparation of baits extracts}


A selection of baits was purchased from different rodenticide suppliers and tested for diastereoisomers proportions. $0.50( \pm 0.01) \mathrm{g}$ of bait was sampled and homogenized with exactly $10 \mathrm{~mL}$ of methanol using a mechanical rotator during $30 \mathrm{~min}$. The mixture was centrifuged at $3000 \mathrm{rpm}$ for $5 \mathrm{~min} .1 \mathrm{~mL}$ of the supernatant was filtered through a $0.2 \mu \mathrm{m}$ phenex filter (Phenomenex, Torrance, CA, USA) and eventually diluted with methanol before LC-MS/MS analysis.

\subsection{Method validation}

The method was fully validated according to the guideline on Bioanalytical Method Validation published by the European Medicines Agency (EMEA) [31] with respect to specificity, carry-over, Lower Limit Of Quantification (LLOQ), calibration curve, accuracy, precision, dilution integrity, matrix effect and stability and this is detailed below.

\subsubsection{Specificity}

The specificity of the method was evaluated by analyzing blank rat liver using 6 different rats. The evaluation of interferences response should be less than $20 \%$ of the LLOQ [31].

\subsubsection{Calibration curves and Lower Limit Of Quantification (LLOQ)}

Blank liver of rats were spiked to obtain six different concentrations $(n=2)$ over the expected calibration range. Calibration curves were established by plotting peak areas versus the expected concentrations. A polynomial regression and a correlation coefficient $\left(r^{2}>0.99\right.$ required) were determined for each compound.

\subsubsection{Precision and accuracy}

The within/between-run precision and accuracy were determined by analysing five replicates at four different Quality Control (QC) levels, on two different days for the between-run precision/accuracy. Precision (expressed as the coefficient of variation (CV)) and accuracy (expressed as the percentage of the nominal value) should not exceed $15 \%$ ( $20 \%$ for LLOQ) and $\pm 15 \%$ ( $\pm 20 \%$ for the LLOQ) respectively [31]. 


\subsubsection{Extraction recovery and matrix effect}

Extraction recovery and matrix effect were calculated using the same set of blank samples of six different rats. Extraction recovery was assessed by comparing processed spiked samples and blank samples spiked after processing. Matrix effect was measured by comparing the response of the processed blank samples and non processed samples (reconstitution solution) spiked at the same level. The CV of matrix effect for the six rats should not exceed $\pm 15 \%$ [31].

\subsection{Sampling of wild rats}

In order to control a population of wild rats officially unexposed to ARs in a French public park from the Parisian suburb, rats have been trapped and killed. Liver of rats has been collected and frozen stored at $-18^{\circ} \mathrm{C}$ until sample processing for ARs quantification.

\section{Results and discussion}

\subsection{Optimization of LC-MS/MS conditions}

First of all, we had to find a column able to separate the five pairs of diastereoisomers of our study in a single run. We decided to test different Core-shell columns and amongst them we chose Poroshell 120 StableBond $\mathrm{C} 18$ for its robustness to biological samples. The defined gradient was important to separate diastereoisomers of the five SGARs and to have retention of the three first generation anticoagulant rodenticides that were more hydrophilic than SGARs.

Diastereoisomers have same chemical structure except for spatial arrangement, and close chemical properties. As the number of LC-MS/MS buffer modifiers is limited, the choice of stationary phase for chromatographic separation is crucial in multi-residue quantitative analysis, especially considering isobaric and/or diastereoisomers compounds. Core-shell technology columns, with partially porous particles, were designed to improve efficiency, minimizing peak width and thus enhancing peak resolution and signal to noise ratios. They tend to UHPLC properties for the Van Deemter equation and high chromatographic separations with low back pressure, making it possible to run on most HPLC instruments. Hayes and al. [28] presented the structure of the Core-shell particles, discussed the advantages to use such a stationary phase. They also analysed the contribution of the different 
terms of the Van Deemter equation for Core-shell particles and fully porous silica columns. They considered one of the future developments for Core-shell columns laid in the separation of isomers or molecules with very similar structure and properties, and complex life matrices.

We tested several $\mathrm{pH}$ conditions for the mobile phase, and ammonium acetate $10 \mathrm{mM}(\mathrm{pH}=5.7)$ has been chosen as aqueous phase. More acidic conditions (ammonium acetate 10mM, adjusted to $\mathrm{pH}=4.8$ with acetic acid) gave enlarged peak shape for chlorophacinone. More basic conditions (ammonium bicarbonate $10 \mathrm{mM}, \mathrm{pH}=7$ ) did not allow chromatographic separation for whichever SGARs diastereoisomers but only BROMA with the poroshell column. Porous particles C18 columns did not even separate BROMA diastereoisomers in basic conditions [19, 27], and did not separate diastereoisomers of the other SGARs with LC-MS/MS buffer modifiers [18-23, 26], even with sub-2 $\mu$ m UHPLC columns [2, 23].

BROMA diastereoisomers were obviously the easiest to separate amongst the five SGARs as we always obtained two separated peaks with Poroshell 120 StableBond $\mathrm{C} 18$ independent of $\mathrm{pH}$ conditions ; chemical structure of BROMA is different from the other SGARs. DFM, BFM, FLO or DFTL have the same 1,2,3,4-tetrahydronaphtyl-4-hydroxycoumarin (A) or 1,2,3,4-tetrahydronaphtyl-4hydroxythiocoumarin (B) moiety respectively, with the two asymmetric carbons standing on that side of the molecules (figure 1), (A) and (B) being differentiated only by a sulfur atom in the place of an oxygen atom for DFTL. BROMA does not hold the (A) or (B) moiety and this may explain why we observed that the diastereoisomeric chromatographic separation was different between BROMA and the other SGARs.

As previously described with an ion trap mass spectrometer instrument [20], MS/MS detection was realised in negative mode. Triple quadripole conditions, i.e. fragmentor voltage (FV), collision energy (CE) and ion fragments for quantification or qualification have been optimised for every compound and are reported in table2. The MRM transitions are shown in figure2. It was then noticed that mass fragments and ratio between quantifier and qualifier ions abundance were the same for every couple of major and minor diastereoisomers. This was a result of the closeness of their chemical structures, and it confirmed the fact that triple quadripole mass spectrometer detector was blind to distinguish two diastereoisomers and that chromatographic separation was required.

3.2. Method validation 


\subsubsection{Specificity}

Typical chromatograms of blank rat liver extract and blank rat liver spiked at LLOQ levels with the thirteen ARs, considering the five pairs of diastereoisomers and ratios as described in table1, are illustrated in figure2. Evidence was made that interferences heights were less than $20 \%$ of LLOQ heights.

\subsubsection{Calibration ranges and lower limit of quantification (LLOQ)}

The correlation coefficients $r^{2}$, linear range and LLOQ for the thirteen ARs are listed in table 3. Second order polynomial regressions performed well since correlation coefficients were higher than 0.99 as required. LLOQ were determined to be accurate, and being at least 5 times the blanks responses.

\subsubsection{Precision and accuracy}

The results for intra/inter-day precision and accuracy, measured for the four QC samples, are summarized in Table 4. The CV\% values for precision of the different ARs were less than $15 \%(20 \%$ for LLOQ), and the values for accuracy were $\pm 15 \%$ ( $\pm 20 \%$ for LLOQ) of the nominal values of the spiked concentrations. The method was then accurate and reproducible for the quantification of the five pairs of diastereoisomers plus three others ARs in rat liver.

\subsubsection{Matrix effect and extraction recovery}

The results for matrix effect and extraction recovery are summarized in Table 5 . The CV\% values for the matrix effect of the different ARs were less than $15 \%$ permitting to conclude there was low matrix effect for the quantification of the five pairs of diastereoisomers plus three others ARs in rat liver. The extraction recovery was between 72.9 and $109.0 \%$ with standard deviation SD less than $12.5 \%$.

\subsubsection{Stability}

The samples stability was demonstrated by re-injecting triplicates of QC samples 24 hours after processing (post extraction stability) at the same spiked concentration levels as for matrix effect and extraction recovery. The same procedure was done for samples spiked and stored in the freezer ($18^{\circ} \mathrm{C}$ ) during 28 days to test the long term stability. The results met the acceptance criteria as the mean concentrations of the triplicates were within $\pm 15 \%$ of the nominal concentrations. 


\subsubsection{Dilution integrity}

Dilution integrity was demonstrated by appropriate spiked processed samples ( $n=5$ per diluted concentration) above the upper limit of quantification (ULOQ) then diluted with blank matrix. Dilution factor $1 / 10$ was investigated. Accuracy and precision were correct (CV $\leq \pm 15 \%)$.

\subsubsection{Conclusion of the validation}

The method Coreshell-LC-MS/MS for multi-residual quantification of ARs in liver of rats has been fully validated according to the EMEA bio-analytical guideline [31].

For the thirteen ARs, LLOQ was between 0.92 and $2.20 \mathrm{ng} / \mathrm{g}$ which is better than LLOQ already reported in rodent livers with liquid chromatography coupled to mass spectrometry detection $[18,26]$ although those results are not directly comparable to our work because the quantification would not distinguish the diastereoisomers contrary to our multi-residue method. For BROMA, DFM and BFM, the LLOQ is slightly better to previous work but with an injection volume of $20 \mu \mathrm{L}$ [26], and for the other ARs, amongst which DFTL and FLO, the LLOQ is substantially improved with a factor between 45 and 100 compared to previous work with an injection volume of $10 \mu \mathrm{L}$ [19]. It is interesting to note that with our method the injection volume of liver processed samples is only $1 \mu \mathrm{L}$ which means a gain in sensitivity would still be possible with a larger volume. And this small injection volume contributes to the limitation of matrix effects, to the robustness of the method and to the extension of column lifetime. However there is no toxicological need for a better sensitivity because the presence of ARs in liver at low ng per $\mathrm{g}$ levels is not correlated to toxic effects.

The recent work made on the characterization of pharmacokinetics of diastereoisomers of DFM with HPLC UV in Damin et al [14] reported by far higher LLOQ of $162 \mathrm{ng} / \mathrm{g}$ but this method remained an alternative for in vivo experiments. However field samples require high sensitivity and specificity of the analytical detection because we need a comprehensive method to screen simultaneously all ARs available on the world market place and to monitor exposure with high sensitivity, as SGARs are very persistent molecules and remain at ng per $\mathrm{g}$ levels in biological matrices of exposed rodents for weeks and months [5, 32]. Both are achieved with this Coreshell-LC-MS/MS method through the specific and sensitive mass spectrometry triple quadrupole detector, and through the highly selective Coreshell column which allows enhancement of signal to noise ratios and chromatographic separation of 
isobaric analytes with mass spectrometry compatible mobile phase additive and retention times as close as $0.19 \mathrm{~min}$ or $0.20 \mathrm{~min}$ for respectively DFM or DFTL diastereoisomers.

This method is then the first published method allowing the multi-residue quantification of SGARs diastereoisomers, and we propose below in a first place an application to investigate the occurrence of ARs and the proportions of SGARs diastereoisomers in liver of wild rats.

3.7. Application of Coreshell LC-MS/MS ARs quantification to not controlled exposure of wild rats Before quantification of ARs in liver of wild rats, we first evaluated the proportion of diastereoisomers in BROMA, DFM, BFM and DFTL commercial baits using the Coreshell LC-MS/MS multi-residue method and normalization of the peak areas. Results are reported in figure 3 and table 6 with the European official values when not confidential. $n$ was the number of different baits we investigated.

A campaign of wild rodent eradication has been carried through setting of traps in a Parisian park. Quantification of ARs in liver of rats (Rattus norvegicus) was performed using the validated Coreshell LC-MS/MS multi-residue method. When an AR had two diastereoisomers, the proportions of the cis and trans forms were calculated and reported in figure 3 . When a concentration was between the limit of detection (LOD) and the LLOQ, which was the case for some minor diastereoisomers, the proportion of the two diastereoisomers was not calculated (the LOD was defined as being half of the LLOQ).

Although ARs had never been officially used in the park to control rodent populations, they were found in liver of rats, meaningful of a probable use of rodenticides by surrounding resident people. Four SGARs were evidenced: BROMA, DFM, BFM and DFTL.

DFTL baits contained mainly cis-DFTL (>90\%), as reported in figure 3 and table 6 , which explained why only cis-DFTL was evidenced in liver of rats. FLO has never been detected which was not surprising as this SGAR is not commercially available in France.

Unlike BROMA and DFM, BFM diastereoisomers proportions in wild rats were between 39 and $70 \%$ for cis-BFM (figure 3). It is quite heterogeneous and stays around the ones in commercial BFM baits. European official values in baits are still confidential. Cis-BFM was found as being between $48 \%$ and $58 \%$ in technical BFM provided by United States firms that sell BFM and BFM products [25]. Our measures on eleven French commercial baits were coherent with those values and were between 
50.1 and $60.4 \%$ with a mean value at $55.4 \pm 3.9 \%$ (table 6 ). For rats $\mathrm{k}$ and $\mathrm{q}$, the proportion of cis-BFM is respectively 41.8 and $39 \%$ which is quite low compared to above results found in baits, but we supposed that the baits used in this area had proportion of cis-BFM exceptionally low. We concluded that more field samples would be required to evidence a possible evolution of the proportion of diastereoisomers of BFM in liver of rats.

On the contrary and except rat $\mathrm{j}$ (trans-BROMA=78.6\%), every wild rat with BROMA (seven rats) revealed only trans-BROMA (trans-BROMA $=100 \%$ for rats $c, g, m, r, s$ ), and for rat $f$ cis-BROMA was detected but not quantified so we were not able to report the proportions. All the rats with DFM (twelve rats) had mainly cis-DFM, i.e. cis-DFM was between $87 \%$ and $100 \%$, nine out of twelve having only cis-DFM (cis-DFM=100\%) (figure 3). In commercial baits, European official values for the proportion of trans-BROMA and cis-DFM are between 70 and $90 \%$, and between 50 and $80 \%$ respectively. The results of the proportions of MAJOR SGARs we measured on commercial baits reported in table 6 were in agreement with these official values. Proportions of trans and cis BROMA and cis and trans DFM in liver of rats were hence very different from those observed in commercial baits.

Between the time they fed on baits and the time they were trapped, the rats eliminated BROMA and DFM minor diastereoisomers quicker than the Major diastereoisomers. Like probably other rodents, brown rats (Rattus norvegicus) thus change diastereoisomers proportions of SGARs found in their body. These characteristics might arise from a difference in pharmacokinetics of SGARs diastereoisomers in brown rats as already reported in Sprague-Dawley rats [14, 15]. SGARs had been formerly developed to increase ARs persistence and to overcome resistance of rodents to FGARs but at this time no speculation had been done on the environmental consequences of this high persistence on non-target wildlife. By the mean of in vivo experimentations on Sprague-Dawley rats, Damin-Pernik et al $[14,15]$ recently demonstrated the ecotoxicological interest in the stereochemistry of SGARs. For these warfarin susceptible rodents, they showed indeed differences in pharmacokinetics and half-lives of their diastereoisomers and then differences in the persistence of cis or trans-isomers, when the absorption and the properties for inhibiting the VKORC1 target enzyme of ARs were similar. Our results presented on brown rats are strengthening the results formerly obtained on Sprague-Dawley rats for BROMA and DFM. Although more results are needed for confirmation on other species of rodents (mice (Mus musculus), black rat (Rattus ratus), and water voles (Arvicola terrestris)...) this means that predatory wildlife should absorb only small quantities of BROMA and 
DFM minor diastereoisomers when feeding on rats. Secondary exposure of predators (raptors, carnivorous mammals) to rodents is hence different from primary exposure to commercial baits, and the consequences of these modifications should be also analysed from this point of view.

Although the proportion of diastereoisomers still has to be investigated, this represents nowadays an opportunity for rodenticides companies to produce SGARs baits with a good balance between anticoagulant efficacity (ability to kill rodents) and persistence. These newly formulated baits with increased proportion of minor diastereoisomers would possibly help to decrease the quantities of SGARs residues in rodents and contribute to a mitigation of secondary exposure of non target wildlife $[14,15]$

The analytical method developed in this work is a new tool particularly well adapted for the study of this hypothesis, and especially on field samples for which a comprehensive multi-residue, sensitive and specific method is needed. A future work based on diastereoisomers, and on toxicological and ecotoxicological consequences of modifications of the Major/minor ratios in preys and baits would be hence of special interest.

\section{Conclusion}

This study describes the development and validation of a sensitive LC-MS/MS multi-residue method for the quantification of eight ARs, five of them being composed of pair of SGARs diastereoisomers. The novelty of this work was to propose an application of a Core-shell column to achieve the chromatographic separation and the simultaneous validated quantification of those five pairs of diastereoisomers.

We were then able to show that this method permitted to produce original results in the composition of diastereoisomers SGARs in liver of wild rats that had been submitted to uncontrolled chronic exposure through commercial rodenticides baits. In particular, this had for consequence to point out that wild rats were changing diastereoisomers proportions of BROMA and DFM in their body and that might be due to differences in their pharmacokinetics according to Damin-Pernik et al $[14,15]$ results from in vivo experiments. Hence, predatory wildlife should not be much exposed to BROMA and DFM minor diastereoisomers with current baits, and this could lead to an improvement of ecological 
characteristics of rodenticides by decreasing the proportion of the most persistent diastereoisomers in baits.

This Core-shell LC-MS/MS method is particularly well adapted for further exploration of diastereoisomers ratios in rodents in terms of pharmacokinetics, and ecotoxicological consequences. It should be applicable with further partial validation to predatory wildlife biological samples permitting the gathering of original news on proportions of SGARs diastereoisomers in case of secondary exposures or secondary mortal intoxications. Numerous applications of this new method will be used in the next future with complementary validation for the production of novel results in biological matrices (blood, plasma, faeces...) for rodents and their predators, as well as for dogs and cats for clinical purposes when primary intoxications are suspected.

\section{Acknowledgments}

This work was supported by grants ISI n'I1301001W “NEORAMUS” from Bpi France.

\section{References:}

1. A. Hodroge, C. Longin-Sauvageon, I. Fourel, E. Benoit, V. Lattard, Biochemical characterization of spontaneous mutants of rats VKORC1 involved in the resistance to antivitamin K anticoagulants. Archives of Biochemistry and Biophysics 515 (2011) 14-20.

2. J. Vein, D. Vey, I. Fourel, P. Berny, Bioaccumulation of chlorophacinone in strains of rats bioresistant to anticoagulants, Pest Manag Sci. 69(3) (2013) 397-402

3. R. Lasseur, C. Longin-Sauvageon, B. Videmann, M. Billeret, P. Berny, E. Benoit, Warfarin resistance in a french strain of rats, J. Biochem. Mol. Toxic. 19(6) (2005) 379-385

4. A. Buckle, Anticoagulant resistance in the United Kingdom and a new guideline for the management of resistant infestations of Norway rats (Rattus norvegicus Berk.), Pest. Manag. Sci. 69 (2013) 334-341

5. M. Sage, I. Fourel, M. Coeurdassier, J. Barrat, P. Berny, P. Giraudoux, Determination of bromadiolone residues in fox faeces by LC/ESI-MS in relationship with toxicological data and clinical signs after repeated exposure. Environ. Res. 110 (2010) 664-674 
6. B.A. Rattner, R.S. Lazarus, J.E. Elliott, R.F. Shore, N. van den Brink, Adverse outcome pathway and risks of anticoagulant rodenticides to predatory wildlife, Environ. Sci. Technol. 48 (2014) 8433-8445

7. J.J. López-Perea, P.R. Camarero, R.A. Molina-López, L. Parpal, E. Obón, J. Solá, R. Mateo, Interspecific and geographical differences in anticoagulant rodenticide residues of predatory wildlife from the Mediterranean region of Spain, Sci Total Environ. 511 (2015) 259-267

8. N. Ruiz-Suárez, L.A. Henriquez-Hernández, P.F. Valerón, L.D. Boada, M. Zumbado, M. Carnacho, M. Almeida-González, O.P. Luzardo, Assessment of anticoagulant rodenticide exposure in six raptor species from the canary Islands (Spain), Sci Total Environ. 485-486 (2014) 371-376

9. P.J. Thomas, P. Mineau, R.F. Shore, L. Champoux, P.A. Martin, L.K. Wilson, G. Fitzgerald, J.E. Elliott, Second generation anticoagulant rodenticides in predatory birds: probabilistic characterisation of toxic liver concentrations and implications for predatory bird populations in Canada, Environ. Int. 37 (2011) 914-920

10. K.H. Langford, M. Reid, K.V. Thomas, The occurrence of second generation anticoagulant rodenticides in non-target raptor species in Norway, Sci Total Environ. 450-451 (2013) 205208

11. B.M. Masuda, P. Fisher, B. Beaven, Residue profiles of brodifacoum coastal marine species following an island rodent eradication, Ecotox. Environ. Safe. 113 (2015) 1-8

12. M. Coeurdassier, R. Riols, A. Decors, A. Mionnet, F. David, T. Quintaine, D. Truchetet, R. Scheifler, P. Giraudoux, Unintentional wildlife poisoning and proposals for sustainable management of rodents, Conserv. Biol. 28 (2014) 315-321

13. J.R. Cort, P.J. Alperin, H. Cho, Measurement and analysis of diastereoisomer ratios for forensic characterization of brodifacoum, Forensic Sci. Int. 214 (2012) 178-181

14. M. Damin-Pernik, B. Espana, S. Besse, I. Fourel, F. Popowycz, E. Benoit, V. Lattard, Development of an ecofriendly anticoagulant rodenticide based on the stereochemistry of difenacoum, Drug Metab. Dispos. (2016) DOI: 10.1124/dmd.116.071688

15. M. Damin-Pernik, B. Espana, S. Lefebvre, I. Fourel, H. Caruel, E. Benoit, V. Lattard, Management of rodent populations by anticoagulant rodenticides: toward third generation anticoagulant rodenticides, (2016) Drug Metab. Dispos. DOI: 10.1124/dmd.116.073791 
16. FDA, Development of New Stereoisomeric Drugs, 5/1/1992, Last updated 12/07/2014, (1992) http://www.fda.gov/Drugs/GuidanceComplianceRegulatoryInformation/Guidances/ucm122883. $\mathrm{htm}$

17. I. Ali and Hassan Y. Aboul-Enein, Chiral pollutants: Distribution, toxicity and analysis by chromatography and capillary electrophoresis, Johan Wiley \& Sons, New York, USA (2004), ISBN: 0-470-86780-9

18. L. Marek, W. Koskinen, Multiresidue analysis of seven anticoagulant rodenticides by highperformance liquid chromatography/electrospray/mass spectrometry, J. Agr. Food Chem. 55 (2007) $571-576$

19. V. Vandenbroucke, N. Desmet, P. De Backer, S. Croubels, Multi-residue analysis of eight anticoagulant rodenticides in animal plasma and liver using liquid chromatography combined with heated electrospray ionization tandem mass spectrometry, J. Chrom. B 869 (2008) 101110

20. I. Fourel, C. Hugnet, I. Goy-Thollot, P. Berny, Validation of a new LC-MS-MS ion-trap technique for the simultaneous determination of 14 anticoagulant rodenticides, drugs or natural products. J. Anal. Toxicol. 34 (2010) 95-102

21. C. Gómez-Canela, A. Vásquez-Chica, S. Lacorte, Comprehensive characterization of rodenticides in wastewater by liquid chromatography-tandem mass spectrometry, Anal. Bioanal. Chem. 406 (2014) 345-358

22. X. Dong, S. Liang, H. Sun, Determination of seven anticoagulant rodenticides in human serum by ultra-performance liquid chromatography-mass spectrometry, Anal. Methods 7 (2015) 1884-1889

23. S. Bidny, K. Gago, M. David, T. Duong, D. Albertyn, N. Gunja, A validated LC-MS-MS method for simultaneous identification and quantitation of rodenticides in blood, J. Anal. Toxicol. 39 (2015) 219-224

24. M. Imran, H. Shafi, S. Ali Wattoo, M.T. Chaudhary, H.S. Usman, Analytical methods for determination of anticoagulant rodenticides in biological samples, Forensic Sci. Int. 253 (2015) 94-102 
25. K. Hunter, E.A. Sharp, A. Newton, Determination of diastereoisomers of bromadiolone, an anticoagulant rodenticide, in animal tissues by High-Performance Liquid Chromatography, J. Chromatogr. 435 (1988) 83-95

26. A.M. Hernández, J. Bernal, J.L. Bernal, M.T. Martín, C. Caminero, M. Nozal, Analysis of anticoagulant rodenticide residues in Microtus arvalis tissues by liquid chromatography with diode array, fluorescence and mass spectroscopy detection, J. Chrom. B, 925(2013) 76-85

27. D. Vudathala, M. Cummings, L. Murphy, Analysis of multiple anticoagulant rodenticides in animal blood and liver tissue using principles of QuEChERS method, J. Anal. Toxicol. 34 (2010) 273-279

28. R. Hayes, A. Ahmed, T. Edge, H. Zhang, Core-shell particles: Preparation, fundamentals and applications in high performance liquid chromatography, J. Chrom. A 1357 (2014) 36-52

29. I. Ali, Z.A. Al-Othman, N. Nagae, V.D. Gaitonde, K.K. Dutta. Recent trends in ultra-fast HPLC: New generation superficially porous silica columns, J. Sep. Sci. (2012) 35, 3235-3249

30. V. Gonzalez-Ruiz, A.I. Olives, M.A. Martin, Core-shell particles leads the way to renewing high-performance liquid chromatography, Trends in Anal. Chem. 64 (2015) 17-28

31. European Medicines Agency, Guideline on bioanalytical method validation, 21 July 2011 EMEA/CHMP/EWP/192217/2009 Rev.1 Corr. ${ }^{*}$ Committee for Medicinal Products for Human Use

(CHMP) http://www.ema.europa.eu/docs/en_GB/document_library/Scientific_guideline/2011/08/WC500 109686.pdf

32. V. Vandenbroucke, A. Bousquet-Melou, P. De Backer, S. Croubels, Pharmacokinetics of eight anticoagulant rodenticides in mice after single oral administration, J. Vet. Pharmacol. Ther, 31(5) (2008), 437-445 
Table 1. Diastereoisomers ratios of reference materials, stereoisomeric assignation and ARs abbreviation

\begin{tabular}{llll}
\hline ARs & ARs abbreviation & \%Major (stereoisomeric form) & \%minor (stereoisomeric form) \\
\hline warfarin & W & - & - \\
coumatetralyl & CTTL & - & - \\
chlorophacinone & CHL & - & - \\
bromadiolone & BROMA & 77.1 (trans-isomers, SR/RS) & 22.9 (cis-isomers, RR/SS) \\
difenacoum & DFM & 53.7 (cis-isomers, SR/RS) & 46.3 (trans-isomers, RR/SS) \\
brodifacoum & BFM & 59.1 (cis-isomers, SR/RS) & 40.9 (trans-isomers, RR/SS) \\
flocoumafen & FLO & 62.2 (trans-isomers, RR/SS) & 37.8 (cis-isomers, SR/RS) \\
difethialone & DFTL & 45.0 (cis-isomers, SR/RS) & 55.0 (trans-isomers, RR/SS)
\end{tabular}


Table 2. MS/MS dMRM transitions parameters for the 8 ARs

\begin{tabular}{lllllll}
\hline AVK & FV $(\mathrm{V})$ & Parent & Quantifier & Quantifier & Qualifier & Qualifier \\
& & lon & lon & CE $(\mathrm{eV})$ & lon & CE $(\mathrm{eV})$ \\
\hline CTTL & 145 & 291.1 & 247.1 & 21 & 141.1 & 29 \\
W & 130 & 307.1 & 250.1 & 21 & 161.1 & 17 \\
CHL & 165 & 373.1 & 201.1 & 21 & 145 & 21 \\
BROMA & 200 & 525.1 & 250.1 & 37 & 181 & 37 \\
DFM & 200 & 443.1 & 293.1 & 37 & 135.1 & 37 \\
BFM & 220 & 521.1 & 78.9 & 45 & 135.1 & 45 \\
FLO & 215 & 541.1 & 382.1 & 25 & 161.1 & 25 \\
DFTL & 210 & 537.1 & 78.9 & 61 & 151 & 37 \\
\hline
\end{tabular}


Table 3. Correlation coefficients (r2), calibration range, LLOQs and retention time for the thirteen ARs in rat liver.

\begin{tabular}{|c|c|c|c|c|}
\hline ARs & $\begin{array}{l}\text { Correlation } \\
\text { coefficients } \\
\qquad\left(r^{2}\right)\end{array}$ & $\begin{array}{c}\text { Calibration } \\
\text { ranges } \\
(\mathrm{ng} / \mathrm{g})\end{array}$ & $\begin{array}{l}\text { LLOQs } \\
(\mathrm{ng} / \mathrm{g})\end{array}$ & $\begin{array}{l}\text { Retention time } \\
\qquad(\mathrm{min})\end{array}$ \\
\hline CTTL & 0.9994 & $2-1000$ & 2.00 & 4,83 \\
\hline W & 0.9994 & $1-1000$ & 1.00 & 5,30 \\
\hline $\mathrm{CHL}$ & 0.9992 & $2-1000$ & 2.00 & 6,61 \\
\hline Trans-BROMA & 0.9993 & $1.54-771$ & 1.54 & 7,70 \\
\hline Cis-BROMA & 0.9999 & $0.92-229$ & 0.92 & 8,13 \\
\hline Cis-DFM & 0.9981 & $1.07-537$ & 1.07 & 8,35 \\
\hline Trans-DFM & 0.9966 & $1.85-463$ & 1.85 & 8,54 \\
\hline Cis-BFM & 0.9990 & $1.18-591$ & 1.18 & 10,02 \\
\hline Trans-BFM & 0.9991 & $1.64-409$ & 1.64 & 10,29 \\
\hline Trans-FLO & 0.9991 & $1.24-622$ & 1.24 & 10,14 \\
\hline Cis-FLO & 0.9988 & $1.51-378$ & 1.51 & 10,56 \\
\hline Cis-DFTL & 0.9989 & $1.8-450$ & 1.80 & 11,15 \\
\hline Trans-DFTL & 0.9989 & $2.2-550$ & 2.20 & 11,35 \\
\hline
\end{tabular}


Table 4. Precision and accuracy for the thirteen ARs in rat liver.

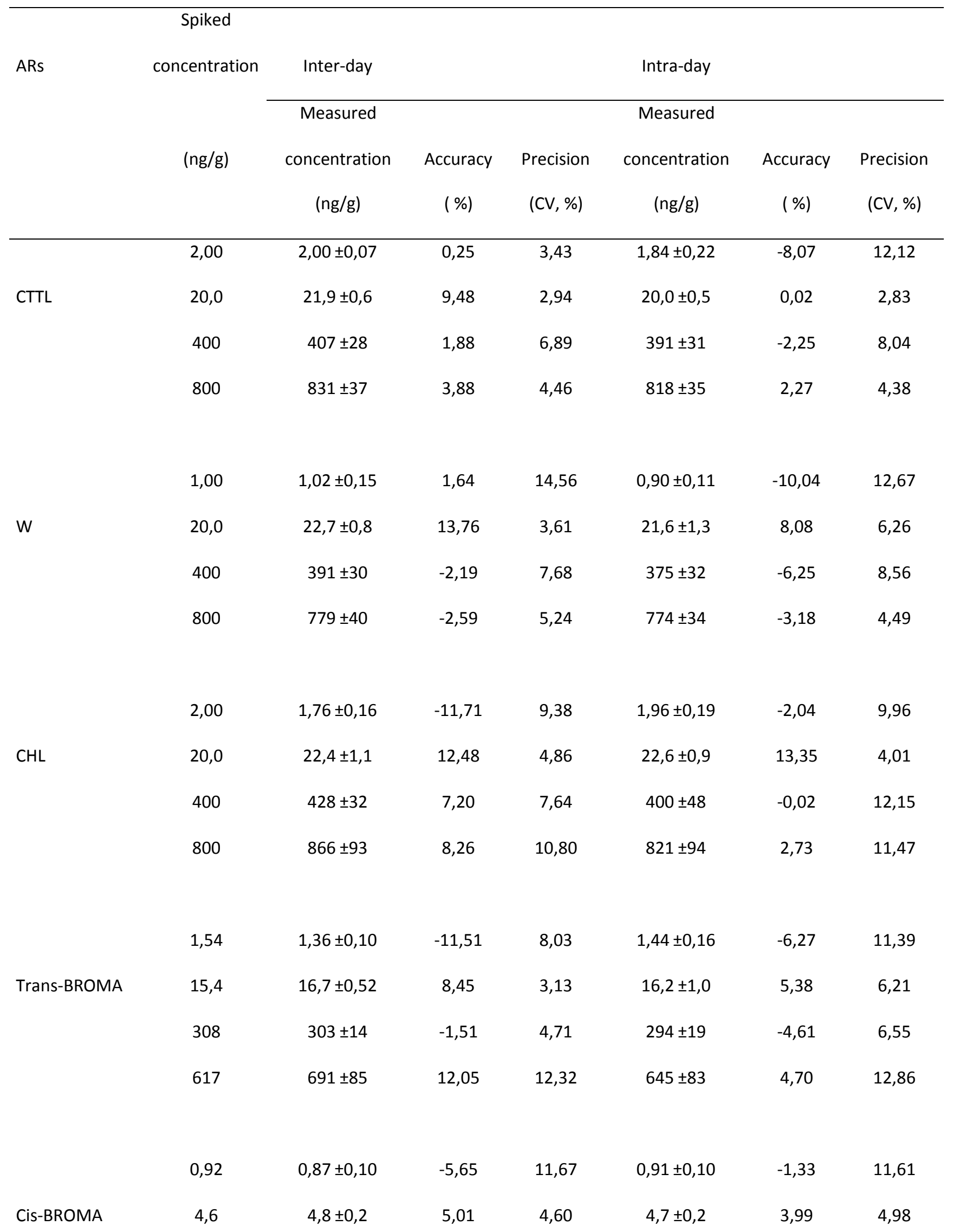




\begin{tabular}{|c|c|c|c|c|c|c|c|}
\hline & 92 & $91 \pm 2,8$ & $-0,04$ & 3,07 & $88 \pm 6$ & $-4,04$ & 6,73 \\
\hline & 183 & $193 \pm 18$ & 5,53 & 9,51 & $186 \pm 17$ & 1,41 & 9,36 \\
\hline & 1,07 & $0,94 \pm 0,04$ & $-11,95$ & 4,67 & $1,10 \pm 0,12$ & 3,38 & 11,18 \\
\hline Cis-DFM & 10,7 & $11,9 \pm 0,9$ & 11,30 & 7,66 & $11,2 \pm 1,2$ & 4,44 & 11,11 \\
\hline & 215 & $205 \pm 10$ & $-4,57$ & 5,16 & $198 \pm 11$ & $-7,38$ & 5,83 \\
\hline & 430 & $434 \pm 57$ & 1,22 & 13,14 & $427 \pm 45$ & $-0,55$ & 10,67 \\
\hline & 1,85 & $1,59 \pm 0,06$ & $-14,10$ & 4,02 & $1,64 \pm 0,08$ & $-11,06$ & 5,08 \\
\hline Trans-DFM & 9,3 & $10,5 \pm 1,1$ & 12,99 & 10,44 & $9,7 \pm 1,1$ & 4,74 & 11,42 \\
\hline & 185 & $188 \pm 10$ & 1,98 & 5,48 & $179 \pm 15$ & $-3,15$ & 8,59 \\
\hline & 370 & $363 \pm 40$ & $-1,95$ & 11,01 & $359 \pm 31$ & $-2,88$ & 8,69 \\
\hline & 1,18 & $1,28 \pm 0,15$ & 8,45 & 11,77 & $1,28 \pm 0,11$ & 9,27 & 8,63 \\
\hline Cis-BFM & 11,8 & $11,3 \pm 0,8$ & $-4,09$ & 7,19 & $11,5 \pm 0,7$ & $-2,40$ & 6,00 \\
\hline & 236 & $248 \pm 8$ & 4,98 & 3,14 & $233 \pm 21$ & $-1,03$ & 9,10 \\
\hline & 473 & $530 \pm 44$ & 12,13 & 8,39 & $492 \pm 56$ & 4,19 & 11,50 \\
\hline & 1,64 & $1,72 \pm 0,13$ & 4,94 & 7,53 & $1,58 \pm 0,18$ & $-3,63$ & 11,54 \\
\hline Trans-BFM & 8,2 & $8,1 \pm 0,5$ & $-0,55$ & 6,88 & $8,0 \pm 0,5$ & $-1,81$ & 6,09 \\
\hline & 164 & $166 \pm 5$ & 1,95 & 3,43 & $158 \pm 12$ & $-3,14$ & 7,90 \\
\hline & 327 & $363 \pm 33$ & 11,07 & 9,34 & $342 \pm 39$ & 4,53 & 11,56 \\
\hline & 1,24 & $1,27 \pm 0,12$ & 2,88 & 9,39 & $1,26 \pm 0,08$ & 1,76 & 6,98 \\
\hline Trans-FLO & 12,4 & $12,7 \pm 1,0$ & 2,17 & 7,74 & $12,3 \pm 0,9$ & $-0,75$ & 7,47 \\
\hline & 249 & $242 \pm 12$ & $-2,73$ & 5,07 & $233 \pm 15$ & $-6,08$ & 6,59 \\
\hline & 498 & $521 \pm 47$ & 4,86 & 9,01 & $508 \pm 40$ & 2,23 & 7,97 \\
\hline
\end{tabular}




\begin{tabular}{|c|c|c|c|c|c|c|c|}
\hline & 1,51 & $1,62 \pm 0,16$ & 7,81 & 10,18 & $1,46 \pm 0,22$ & $-3,24$ & 15,14 \\
\hline \multirow[t]{4}{*}{ Cis-FLO } & 7,6 & $7,5 \pm 0,5$ & $-0,57$ & 6,21 & $7,4 \pm 0,4$ & $-2,55$ & 5,68 \\
\hline & 151 & $141 \pm 7$ & $-6,73$ & 5,05 & $137 \pm 7$ & $-8,81$ & 5,36 \\
\hline & 302 & $313 \pm 20$ & 3,75 & 6,50 & $304 \pm 20$ & 0,67 & 6,86 \\
\hline & 1,80 & $2,08 \pm 0,20$ & 15,95 & 9,76 & $1,70 \pm 0,30$ & $-5,38$ & 18,58 \\
\hline \multirow[t]{4}{*}{ Cis-DFTL } & 9,0 & $8,8 \pm 0,5$ & $-1,95$ & 5,29 & $8,6 \pm 0,4$ & $-3,46$ & 4,77 \\
\hline & 180 & $167 \pm 2$ & $-7,25$ & 1,47 & $161 \pm 9$ & $-10,32$ & 5,88 \\
\hline & 360 & $374 \pm 22$ & 3,94 & 6,11 & $356 \pm 29$ & $-0,87$ & 8,28 \\
\hline & 2,20 & $2,51 \pm 0,02$ & 14,51 & 1,00 & $2,07 \pm 0,35$ & $-5,85$ & 17,16 \\
\hline \multirow[t]{3}{*}{ Trans-DFTL } & 11,0 & $10,5 \pm 0,6$ & $-4,49$ & 5,36 & $10,44 \pm 0,45$ & $-5,02$ & 4,33 \\
\hline & 220 & $198 \pm 6$ & $-10,10$ & 3,05 & $193 \pm 10$ & $-12,10$ & 5,18 \\
\hline & 440 & $445 \pm 22$ & 1,28 & 4,98 & $428 \pm 28$ & $-2,54$ & 6,70 \\
\hline
\end{tabular}


Table 5. Matrix effect (CV\%) and extraction recovery of the 13 ARs in rat liver $(n=6)$

\begin{tabular}{|c|c|c|c|}
\hline \multirow{4}{*}{ ARs } & \multirow{3}{*}{$\begin{array}{c}\text { Spiked } \\
\text { concentration }\end{array}$} & \multirow{2}{*}{$\begin{array}{l}\text { Matrix } \\
\text { effect }\end{array}$} & \multirow{2}{*}{$\begin{array}{l}\text { Extraction } \\
\text { Recovery }\end{array}$} \\
\hline & & & \\
\hline & & & Mean \pm SD \\
\hline & (ng/g) & CV (\%) & (\%) \\
\hline \multirow[t]{2}{*}{ CTTL } & 20,0 & 4,5 & $89,3 \pm 3,6$ \\
\hline & 800 & 1,9 & $85,6 \pm 3,1$ \\
\hline \multirow[t]{2}{*}{ W } & 20,0 & 5,7 & $102,5 \pm 5,5$ \\
\hline & 800 & 6,2 & $101,8 \pm 5,2$ \\
\hline \multirow[t]{2}{*}{$\mathrm{CHL}$} & 20,0 & 7,4 & $89,2 \pm 5,7$ \\
\hline & 800 & 12,2 & $99,2 \pm 5,2$ \\
\hline \multirow[t]{2}{*}{ Trans-BROMA } & 15,4 & 4,6 & $72,9 \pm 4,8$ \\
\hline & 617 & 8,7 & $83 \pm 2,6$ \\
\hline \multirow[t]{2}{*}{ Cis-BROMA } & 4,6 & 3,6 & $93,2 \pm 12,5$ \\
\hline & 183 & 12,5 & $89,7 \pm 7,8$ \\
\hline \multirow[t]{2}{*}{ Cis-DFM } & 10,7 & 9,5 & $85,3 \pm 9,4$ \\
\hline & 430 & 12,2 & $81,6 \pm 4,9$ \\
\hline \multirow[t]{2}{*}{ Trans-DFM } & 9,3 & 9,1 & $89,0 \pm 6,4$ \\
\hline & 370 & 11,8 & $100,1 \pm 12,1$ \\
\hline Cis-BFM & 11,8 & 2,2 & $90,2 \pm 1,8$ \\
\hline
\end{tabular}




\begin{tabular}{|c|c|c|c|}
\hline \multirow[t]{2}{*}{ Trans-BFM } & 8,2 & 2,6 & $83,6 \pm 3,4$ \\
\hline & 317 & 5,3 & $93,5 \pm 8,5$ \\
\hline \multirow[t]{2}{*}{ Trans-FLO } & 12,4 & 3,7 & $90,2 \pm 1,0$ \\
\hline & 498 & 5,7 & $109,0 \pm 9,7$ \\
\hline \multirow[t]{2}{*}{ Cis-FLO } & 7,6 & 4,7 & $91,6 \pm 2,5$ \\
\hline & 302 & 3,9 & $99,4 \pm 9,0$ \\
\hline \multirow[t]{2}{*}{ Cis-DFTL } & 9,0 & 6 & $88,2 \pm 2,7$ \\
\hline & 360 & 4,2 & $93,8 \pm 5,5$ \\
\hline \multirow[t]{2}{*}{ Trans-DFTL } & 11,0 & 5,9 & $88,2 \pm 2,7$ \\
\hline & 440 & 4,2 & $93,8 \pm 5,4$ \\
\hline
\end{tabular}


Table 6. Proportion of the Major diastereoisomers in commercial baits for BROMA, DFM, BFM and DFTL.

\begin{tabular}{lcccc}
\hline ARs & trans-BROMA & cis-DFM & cis-BFM & cis-DFTL \\
\hline European official & & & & \\
values & $70-\mathbf{9 0 \%}$ & $50-80 \%$ & confidential & confidential \\
\hline $\mathbf{n}$ & 3 & 10 & 11 & 5 \\
\hline mean (\%) & 76,3 & 59,4 & 55,4 & 98,0 \\
\hline SD (\%) & 2,2 & 5,8 & 3,9 & 1,1 \\
\hline
\end{tabular}


Figure1: Chemical structure of SGARs.

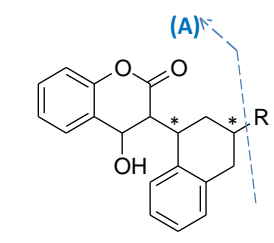

DFM, BFM, FLO

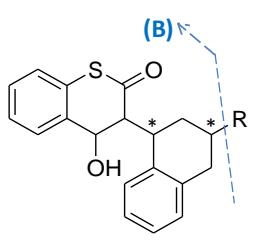

DFTL

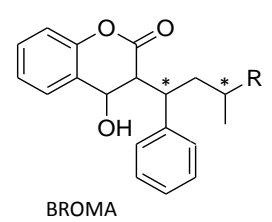

BROMA

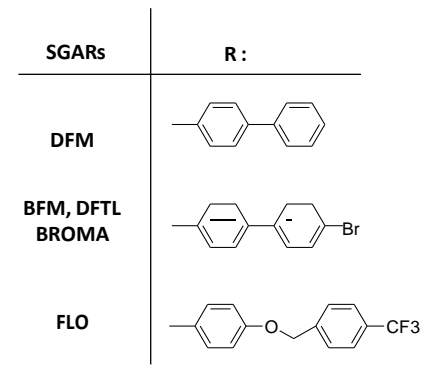


Figure 2. MRM chromatograms of blank rat liver, rat liver spiked at LLOQ with the 13 ARs, retention time and MRM transitions at LLOQ.

Blank

\section{CTTL}

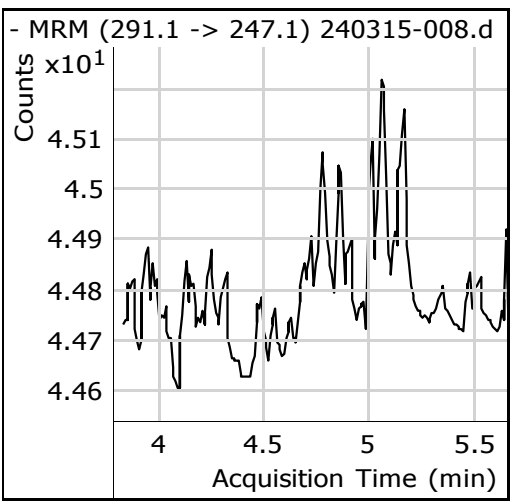

W

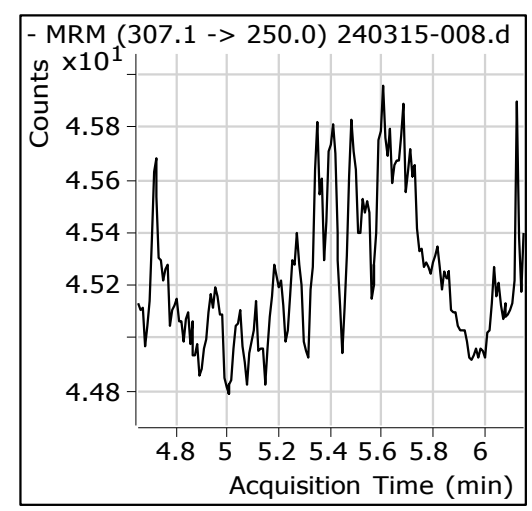

CHL

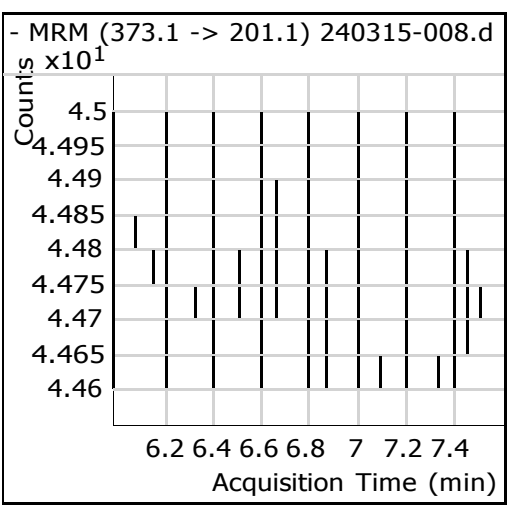

LLOQ, retention time (min)

MRM transitions
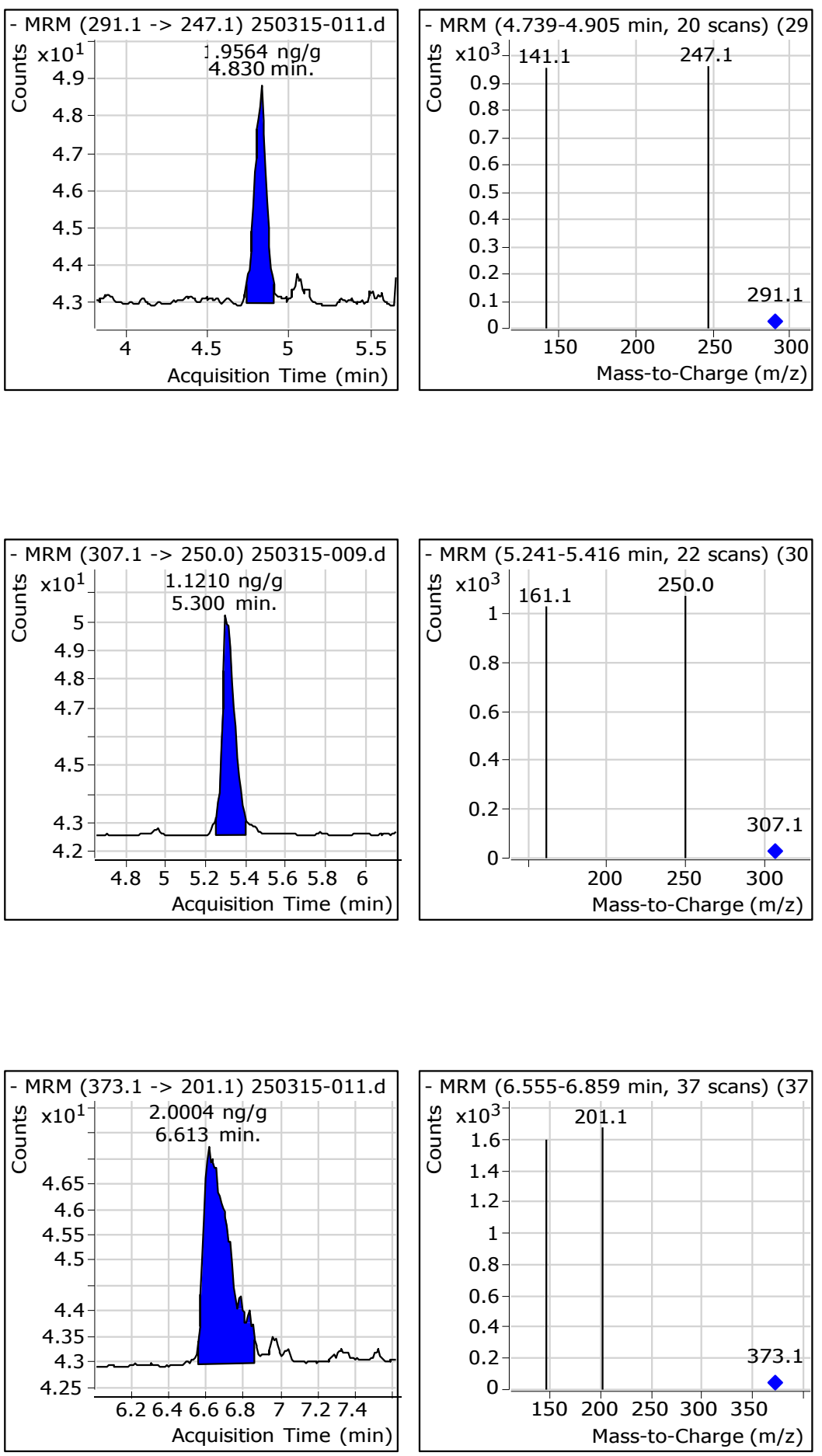
Trans-BROMA Major
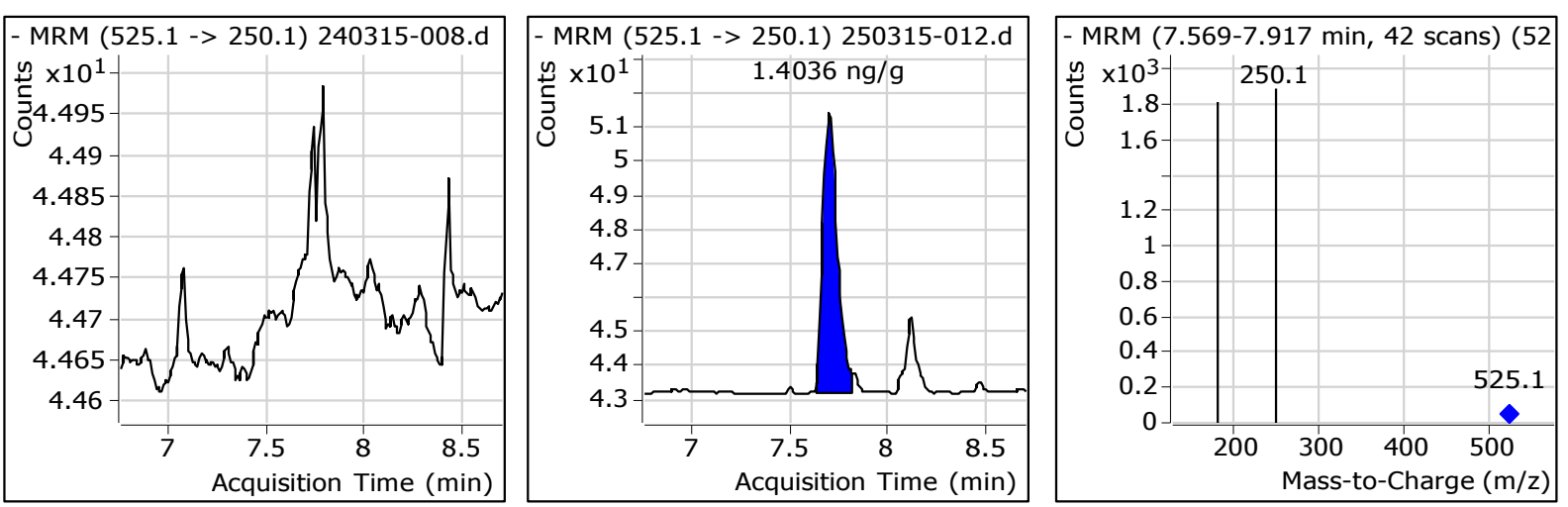

\section{Cis-BROMA minor}
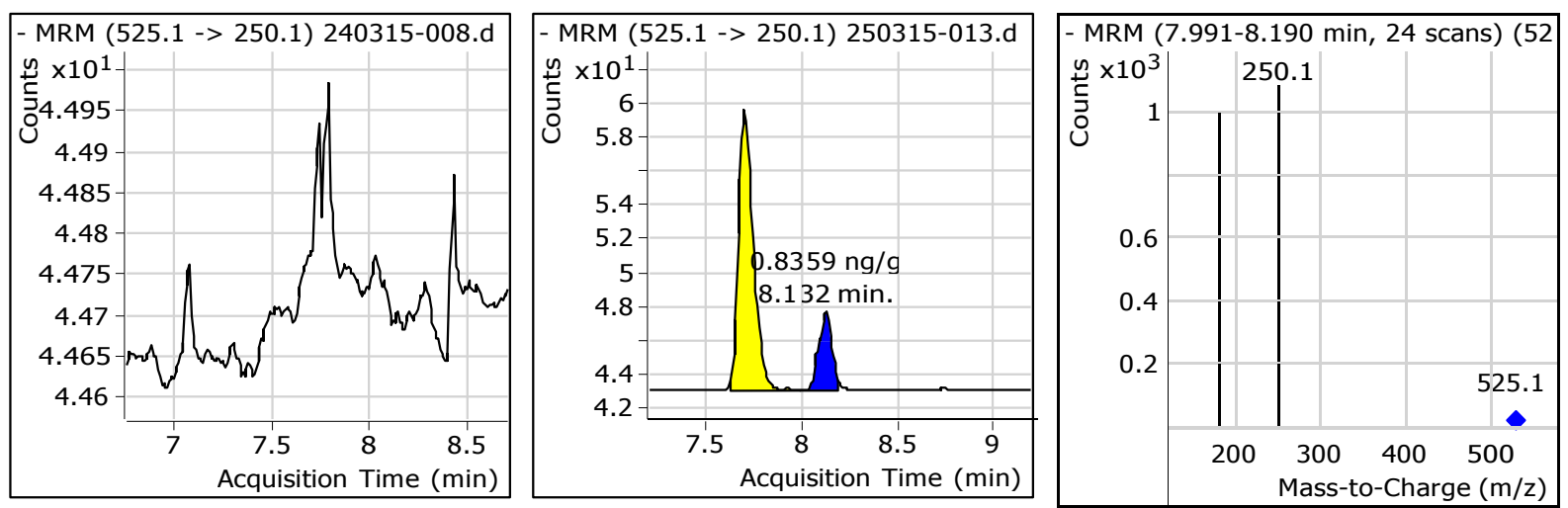

\section{Cis-DFM Major}
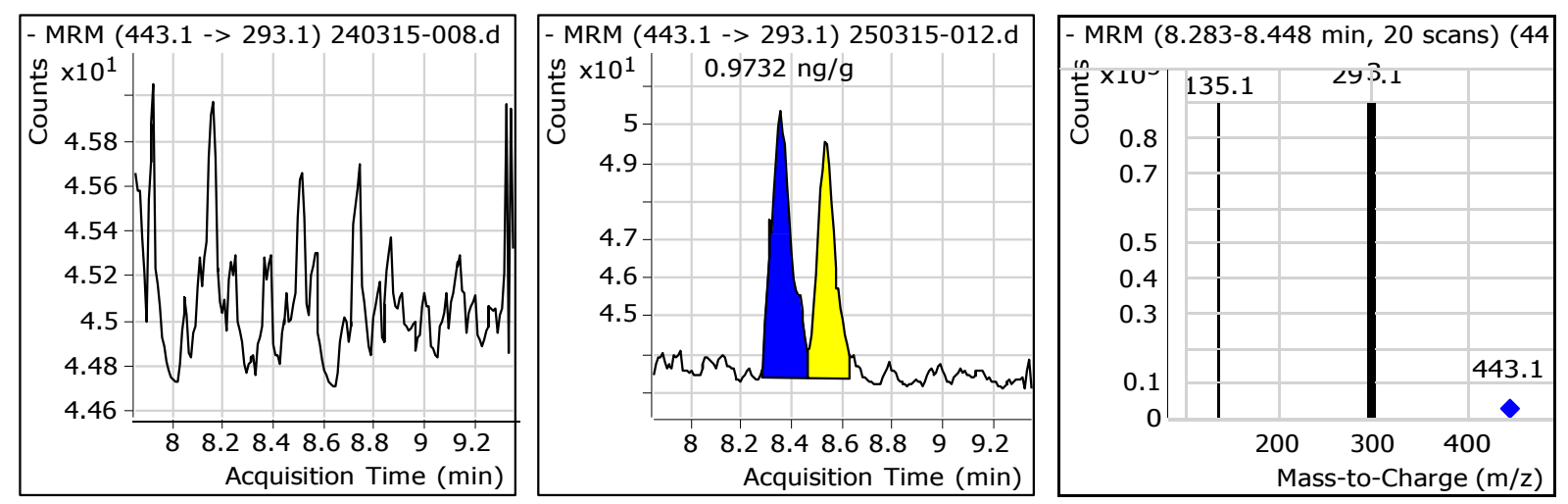
Trans-DFM minor
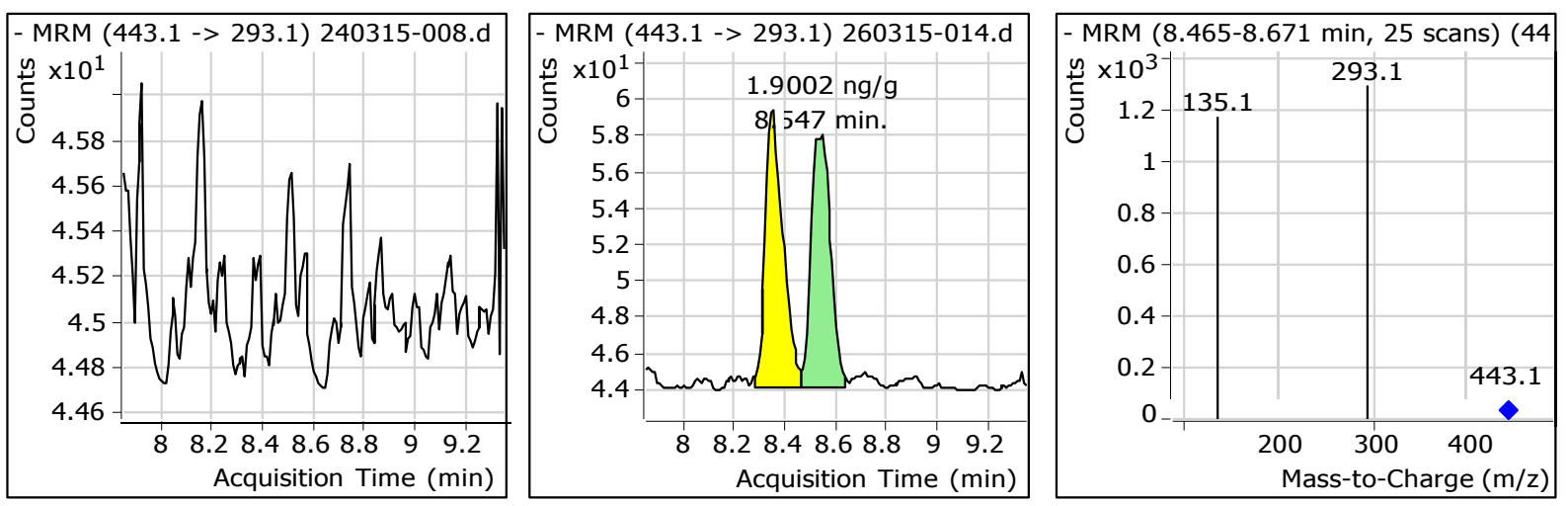

\section{Cis-BFM Major}
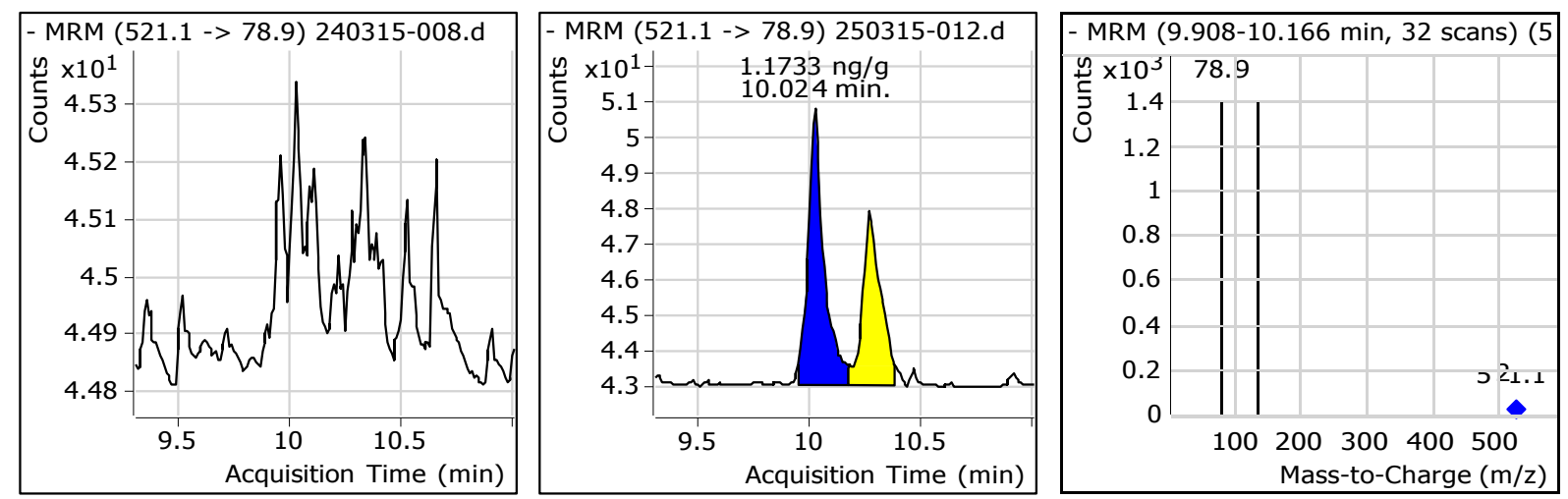

\section{Trans-BFM minor}
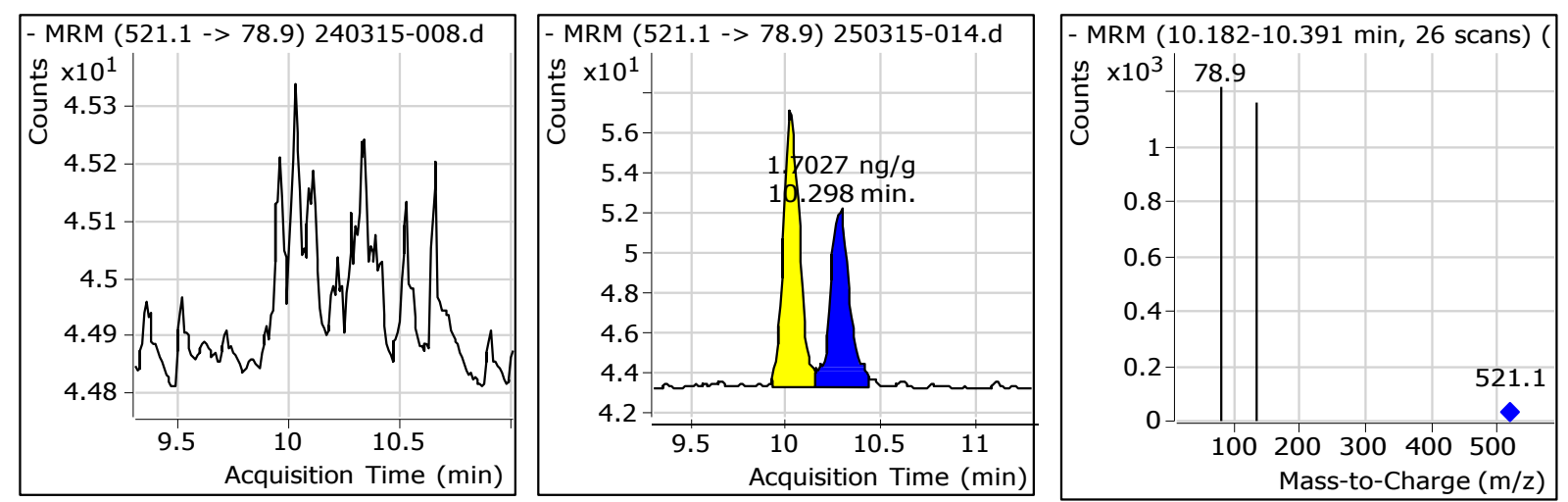


\section{Trans-FLO Major}
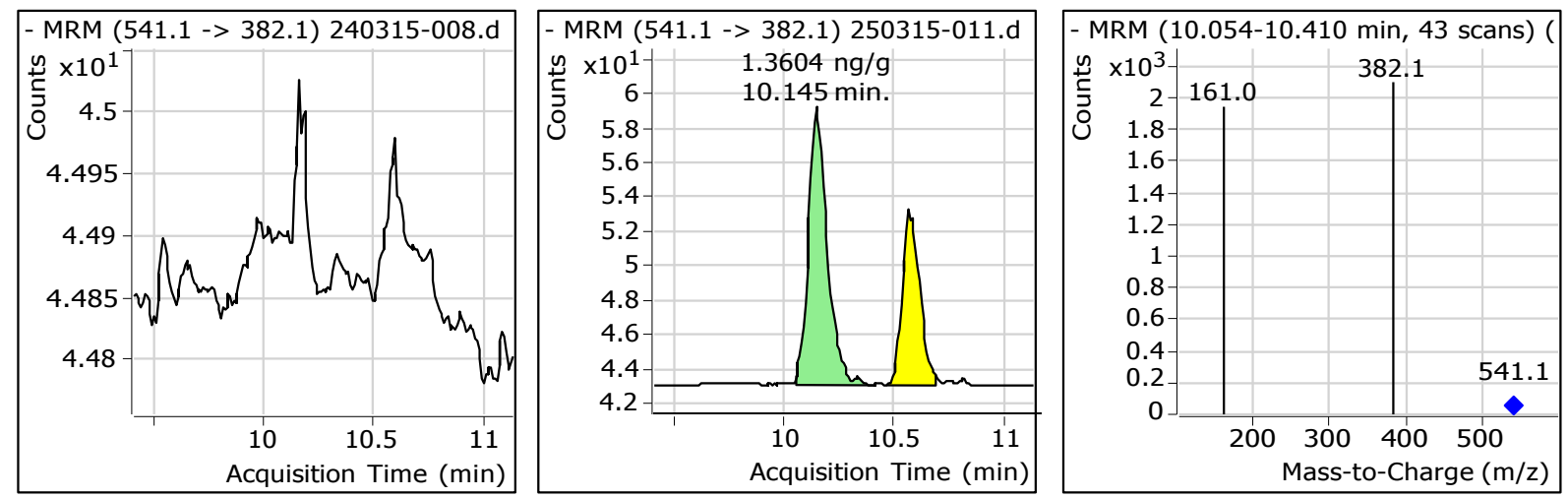

\section{Cis-FLO minor}
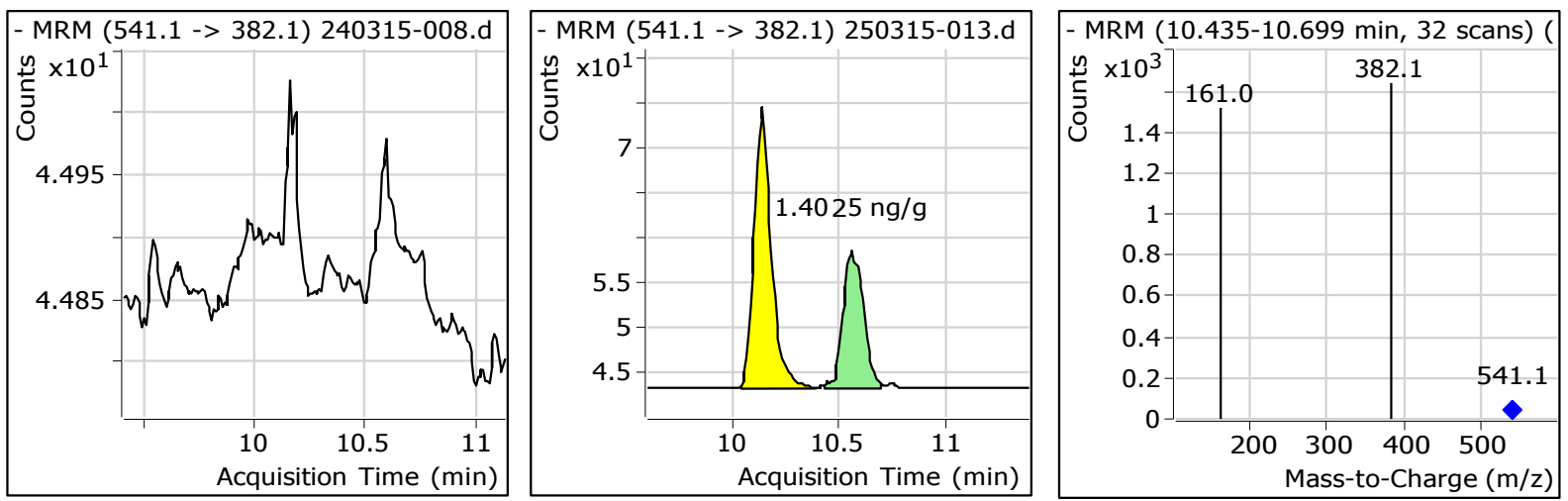

\section{Cis-DFTL Major}
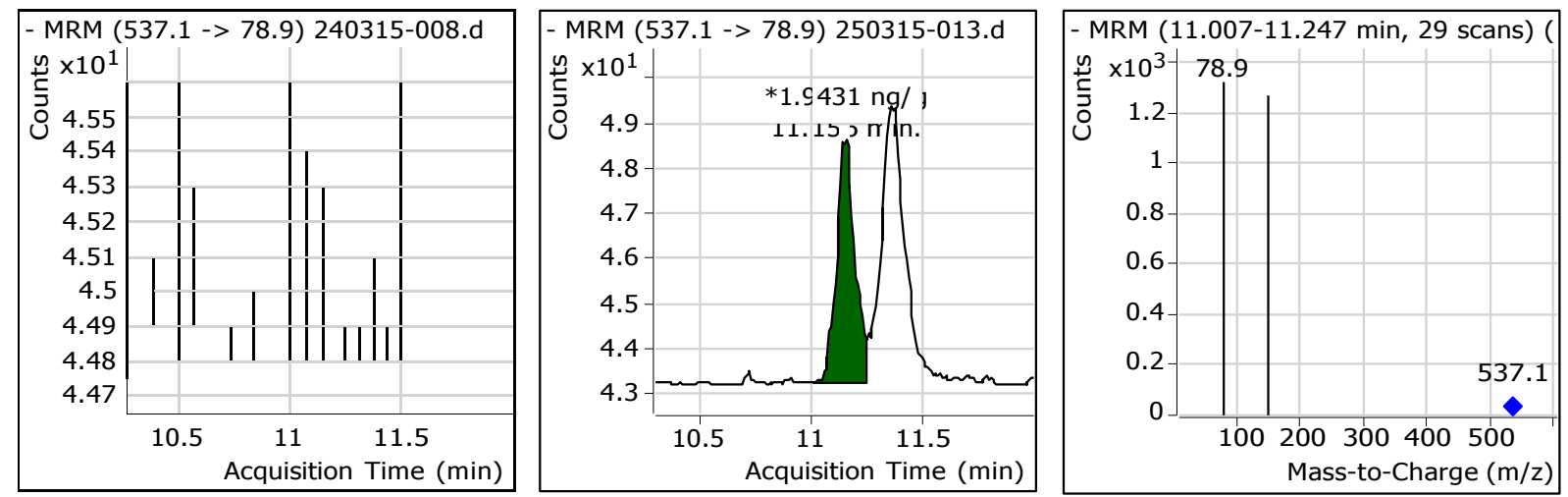


\section{Trans-DFTL minor}
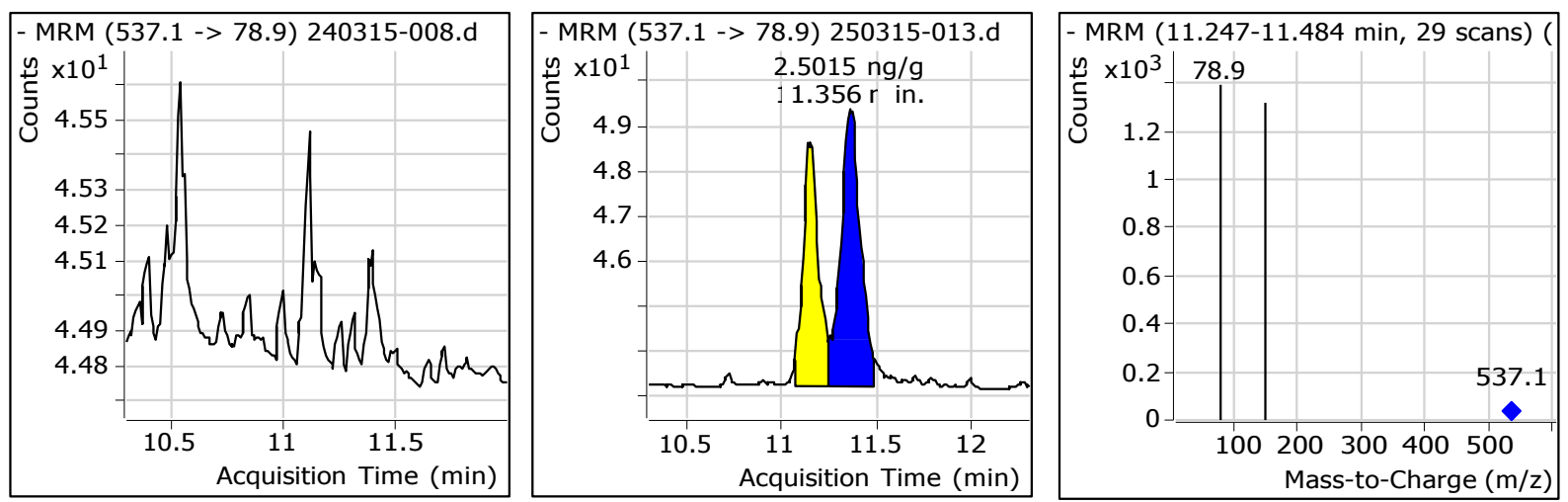
Figure 3. Proportion (\%) of diastereoisomers of BROMA, DFM, BFM, DFTL in liver of wild rats and in baits.
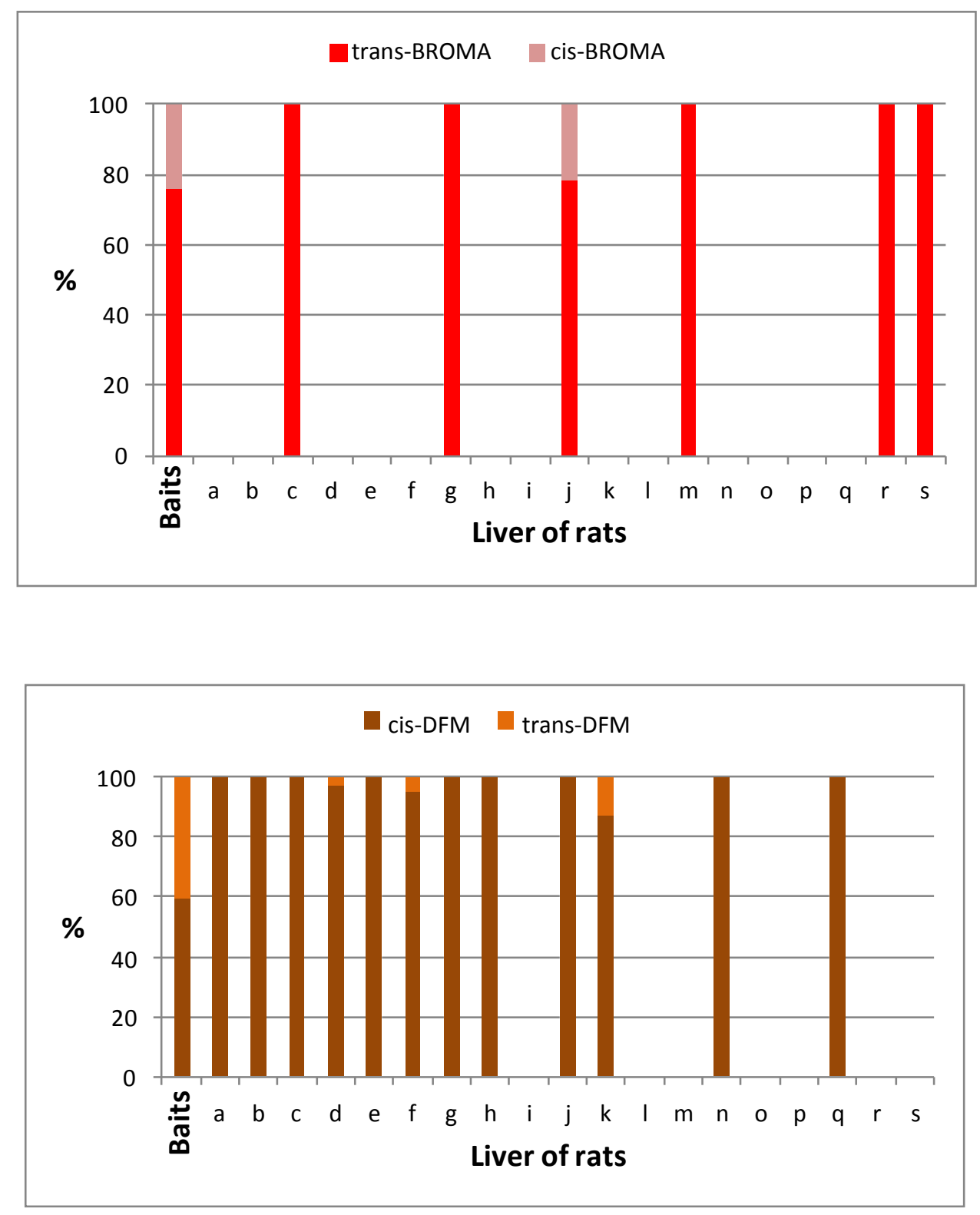

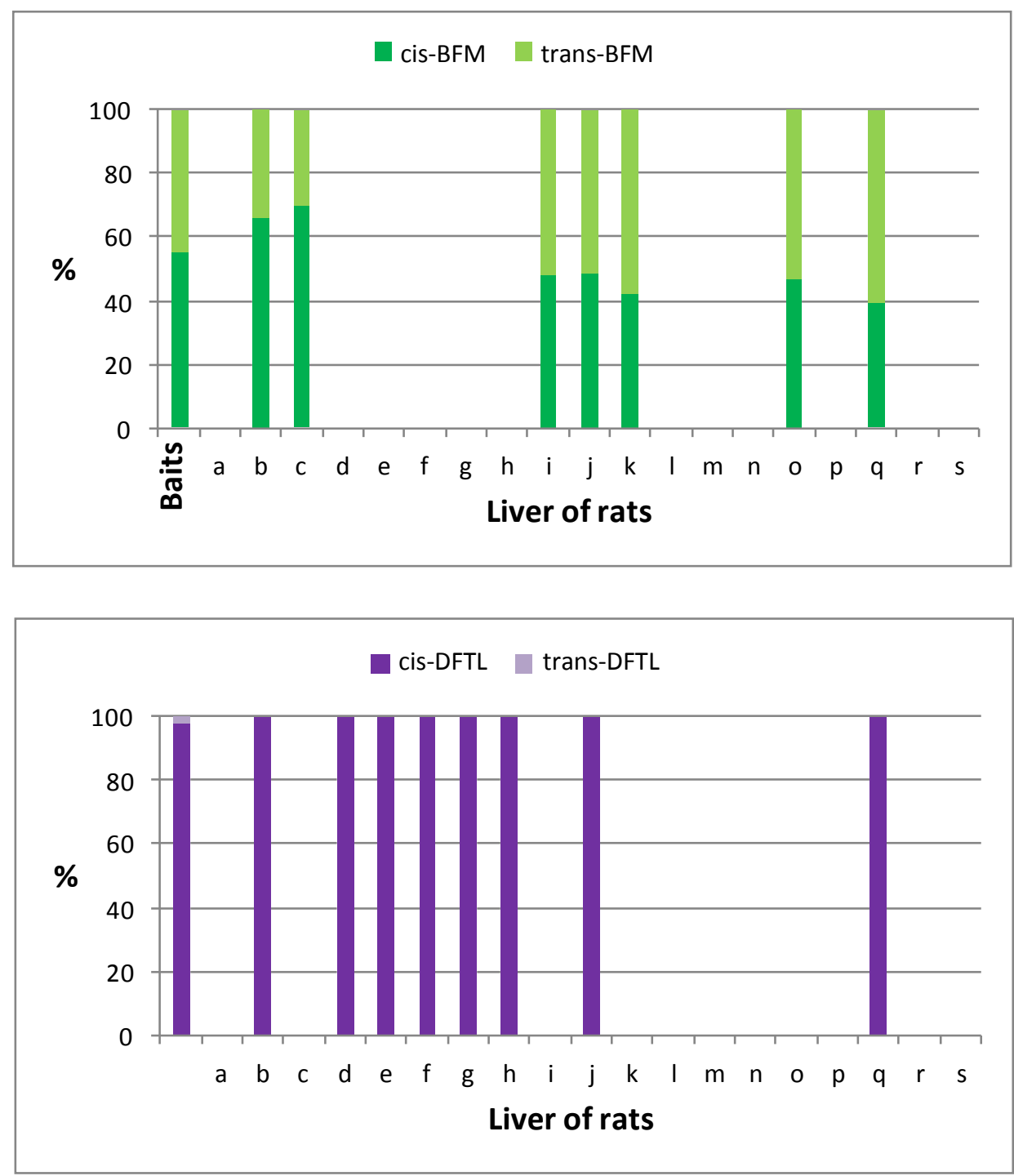


\section{Highlights :}

1) LC-MS/MS quantitative multi-residue method is fully validated to measure rodenticides

2) This method separates five pairs of diastereoisomers with a core-shell column

3) This method is a tool to explore diastereoisomers persistence in wildlife samples

4) Monitoring diastereoisomeric ratios from baits absorption to wildlife samples

5) Diastereoisomers ratios in liver of wild rats and rodenticides baits are different 